\title{
Influence of Dietary Supplementation of Herb Extracts on Volatile Sulfur Production in Pig Large Intestine
}

\author{
Kazunari UshIDA ${ }^{1, *}$, Makiko MAEKAWA ${ }^{1}$ and Tsutomu ARAKAWA ${ }^{2}$ \\ ${ }^{1}$ Laboratory of Animal Science, Kyoto Prefectural University, Shimogamo, \\ Sakyo-ku, Kyoto 606-8522, Japan \\ ${ }^{2}$ Food Material Section, Central Laboratory, Lotte Co., Ltd., \\ Numakage, Urawa, Saitama 336-0027, Japan
}

(Received October 23, 2000)

\begin{abstract}
Summary Volatile sulfur compounds (VS) are generated in the large intestine by the bacterial metabolism of sulfate and sulfur amino acids. VS are potentially harmful to the host. The effect of dietary supplementation of herb extracts on volatile sulfur production in the large intestine of pig was evaluated in this study. The extracts Perilla frutescens (Soyou), Mentha piperita (Peppermint), and Ajuga decumbens (Kiransou) were fed to pigs equipped with a permanent cannula at the cecum. Cecal digesta were sampled and analyzed for ammonia and short-chain fatty acids (SCFA). Sampled digesta were incubated anaerobically either with or without L-methionine for $24 \mathrm{~h}$ to estimate volatile sulfur production in vivo. L-Methionine was supplemented to enhance methanethiol (MeSH) production. At the end of the incubation, head space concentrations of volatile sulfur compounds such as hydrogen sulfide $\left(\mathrm{H}_{2} \mathrm{~S}\right), \mathrm{MeSH}$, and dimethyl sulfide (DMS) were determined by flame-photometric gaschromatography after the addition of $6 \mathrm{~N} \mathrm{HCl}$. Sampled digesta were also subjected to the most probable number estimations for sulfate-reducing bacteria (SRB), sulfide producer from L-methionine, and MeSH producers from L-methionine. All three herb extracts significantly decreased $\mathrm{H}_{2} \mathrm{~S}(p<0.05)$, MeSH $(p<0.05)$, and ammonia $(p<0.05)$ production, but SCFA production was not affected ( $p>0.05$ ). The number of volatile sulfur-producing bacteria did not vary among groups by the dietary supplementation of these herb extracts. Serial solvent extraction was done on these herb extracts to specify the active fractions that reduce volatile sulfur production. $n$-Butanol fraction of all three extracts significantly reduced volatile sulfur production in vitro.
\end{abstract}

Key Words herbs, hydrogen sulfide, methanethiol, large intestine, pig

Volatile sulfur compounds (VS) such as hydrogen sulfide $\left(\mathrm{H}_{2} \mathrm{~S}\right)$, methanethiol $(\mathrm{MeSH})$, and dimethyl sulfide are generated by bacteria in the large intestine. In the intestinal tract, $\mathrm{H}_{2} \mathrm{~S}$ might injure colonocytes (1) and might cause ulcerative colitis (2-4). MeSH produced from L-methionine by intestinal bacteria may cause hepatic encephalopathy in rats, dogs, and cirrhotic patients $(5,6)$. The control of VS production through nutritional or pharmaceutical measures is therefore clinically important. Moreover, these compounds are responsible for fecal odor. The reduction of fecal odor has practical values for humans.

The bacteria that produce VS can reduce free sulfate by the dissimilative pathway and/or desulfhydrate sulfur amino acids by $\alpha$ - or $\beta$ - $\gamma$ lyase. The former group of bacteria is categorized as sulfate-reducing bacteria (SRB) such as Desulfovibrio spp., and the latter involves some species of clostridia and fusobacteria (7-9).

Aminoglycoside antibiotic inhibits luminal sulfide production in ulcerative colitis (10). Removing foods rich in sulfur amino acids such as milk, egg, and cheese improves ulcerative colitis (1). Both suggest the involve-

\footnotetext{
* To whom correspondence should be addressed
}

ment of SRB, clostridia, and some other bacteria that desulfhydrate sulfur amino acids.

We previously selected extracts of European and Oriental herbs that inhibit sulfide production by Desulfovibrio desulfuricans in vitro (11). In the present study, we further evaluated three herb extracts for their capacity to reduce VS production in pig large intestine.

\section{MATERIALS AND METHODS}

Animal and diet. Four cross-bred (Landrace $\times$ Large white $\times$ Duroc) castrated male pigs ( $4-5$ mo old, about $50-60 \mathrm{~kg}$ body weight) were used. They were fistulated with a permanent cecal cannula at least 1.5 mo before the experiment. The pigs were individually kept in metabolic cages and fed a meal mainly composed of cracked maize $(615 \mathrm{~g})$, alfalfa meal $(190 \mathrm{~g})$, and meat bone meal $(190 \mathrm{~g})$ twice a day at 10:00 and 18:00. The diet contained $69.9 \%$ TDN (total digestible nutrients) (12), $13.9 \%$ DCP (digestible crude protein), and $3,060 \mathrm{kcal} / \mathrm{kg}$ DE (digestible energy). The diet was supplemented with vitamin mineral premix (Vitamin ADESan, Kokin Kagaku, Osaka) and $\mathrm{NaCl}$ (13). The diet was expected to support a daily body weight gain of $0.6 \mathrm{~kg}$. Water was always accessible to the animals. All dietary 
components were purchased from Kumiai Shiryo (Kobe).

Herb extracts and experimental design. The following three herb extracts were selected based on the previous in vitro screening experiments (11). The extracts of Perilla frutescens (Soyou), Mentha piperita (Peppermint), and Ajuga decumbens (Kiransou) were prepared as follows. Dried $P$. frutescens leaves $(500 \mathrm{~g}$ ) were extracted in $5 \mathrm{~L}$ of $50 \%$ aqueous ethanol at $80^{\circ} \mathrm{C}$ for $3 \mathrm{~h}$. The latter two herbs were extracted in the same manner as $P$. frutescens, but in $5 \mathrm{~L}$ of distilled water. The extracts contained solid residues at $17.4,22.2$, and $32.3(\mathrm{~g} / \mathrm{L})$, respectively.

These herb extracts were manually mixed with rations and offered to the pigs. A daily dose of these extracts was $83.3 \mathrm{~mL}$, which corresponded to approximately $5 \mathrm{~g}$ of dried herbs.

Because one of the extracts was prepared in 50\% aqueous ethanol, the same amount of ethanol was supplied to all pigs.

The experiment was conducted according to a $4 \times 4$ Latin Square design.

Each period consisted of $10 \mathrm{~d}$ for an adaptation period, followed by an 8-d cecal sampling period. Cecal digesta were collected twice in a sampling period. A period of $7 \mathrm{~d}$ was inserted between the treatment periods, during which the basal diet was given to the animals.

Chemical and microbiological analyses. Cecal digesta (about $100 \mathrm{~g}$ ) were sampled during morning feeding. They were diluted to half strength with $0.05 \mathrm{M} 2$-morphorinoethane sulfonate (MES) buffer ( $\mathrm{pH}$ 6.5) and homogenized by a blender. The buffer was boiled under nitrogen gas before use. Homogenates were squeezed through two layers of surgical gauze. A portion $(5 \mathrm{~mL})$ of filtrate was dispensed into $10 \mathrm{~mL}$ serum vials. The remainder was analyzed for short chain fatty acids (SCFA) (14) and ammonia (15). The vials were closed with butyl rubber septa and aluminum seals. All manipulations were done under the stream of $\mathrm{O}_{2}$-free nitrogen. Three vials were incubated without extra substrate. Three other vials were added L-methionine at $1 \%(\mathrm{w} / \mathrm{v})$ to stimulate MeSH production. All vials were placed at $37^{\circ} \mathrm{C}$ for $24 \mathrm{~h}$ with 2 to 3 gentle shakings. At the end of incubation, $6 \mathrm{~N} \mathrm{HCl}(1 \mathrm{~mL})$ was added to the vials to stop fermentation. VS in the headspace was analyzed by a flame photometric detector-gaschromatography (FPD-GC) (16).

One gram of cecal digesta was subsampled from the cecal digesta taken on the first sampling in each experimental period and subjected to 10-fold serial dilution with an anaerobic dilution solution (17) and inoculated to SRB-selective medium and modified Gifu anaerobic medium (GAM). SRB-selective medium was prepared according to Arakaki et al. (17), and modified GAM was prepared as indicated by the manufacturer's instruction (Nissui, Tokyo). The latter was supplemented with Lmethionine $(0.5 \% \mathrm{w} / \mathrm{v})$. The number of SRB was estimated by the most probable number (MPN) technique (17) by judging SRB positive based on the formation of black precipitation after $14 \mathrm{~d}$ incubation at $37^{\circ} \mathrm{C}$. The number of MeSH-producing bacteria was also estimated by an MPN technique according to the formation of $\mathrm{MeSH}$ in the headspace gas. MeSH production was judged positive if the concentration was higher than $10 \mathrm{ppm}$. The smallest positive values for MeSH level were approximately $100 \mathrm{ppm}$ in the present study. $\mathrm{H}_{2} \mathrm{~S}$ production was also determined and used for the estimation of sulfide-producing bacteria by MPN technique. The smallest positive values for $\mathrm{H}_{2} \mathrm{~S}$ was approximately $150 \mathrm{ppm}$ in the headspace gas.

Serial organic solvent fractionation and detection of active components. Herb extracts were serially extracted by $n$-hexane, diethylether, chloroform, ethylacetate, and $n$ butanol to fractionate the active compounds in separating funnels. The organic solvents were totally removed from these extracts by a rotary evaporator under reduced pressure. Thus dried materials were dissolved into 2 to $5 \mathrm{~mL}$ dimethyl formamide (DMF). One of these solutions corresponding to $10 \mathrm{mg}$ dried materials $/ \mathrm{mL}$ in a culture fluid was added to the in vitro pig cecal fermentation system stated above. This dose was determined according to our previous result (11). At the end of incubation, VS in headspace gas was determined as described above.

Statistical analyses. Statistical analyses were performed according to Yoshida (18) by the use of a oneway analysis of variance (ANOVA) to evaluate the effect of herb extracts by StatView ver 5.0 (Brain Power, Inc., Calabasas, CA, USA). When the effect of diet (supplementation of herb extracts) was judged to be significant $(p<0.05)$, a post hoc Tukey-Kramers test was done by StatView ver 5.0.

\section{RESULTS}

Effect of dietary herb extracts on cecal VS production (Table 1)

VS in the headspace gas at $0 \mathrm{~h}$ incubation was not detected by the present analytical method. Therefore VS concentration in the headspace gas at $24 \mathrm{~h}$ culture was regarded to represent VS production during $24 \mathrm{~h} . \mathrm{H}_{2} \mathrm{~S}$ was the only detectable VS in cultures without the supplementation of L-methionine, and $\mathrm{H}_{2} \mathrm{~S}$ and $\mathrm{MeSH}$ were detected in L-methionine-supplemented incubations with the occasional detection of small amounts of dimethyl sulfide and dimethyl disulfide (Table 1).

All three herb extracts reduced $\mathrm{H}_{2} \mathrm{~S}$ production $(p<0.05)$ in cultures without the supplementation of $\mathrm{L}-$ methionine. $\mathrm{H}_{2} \mathrm{~S}$ was reduced to approximately half as much as control incubation. In the L-methionine-supplemented cultures, MeSH production was significantly decreased by all three herb extracts $(p<0.01)$ to $70 \%$ of control incubation. $\mathrm{H}_{2} \mathrm{~S}$ production in the L-methionine-supplemented cultures was also significantly reduced by herb extracts, except for that of $A$. decumbens. Effect of dietary herb extracts on cecal SCFA and ammonia production (Table 2)

Three herb extracts did not significantly affect the SCFA concentrations, except for acetate. However, none of the extracts significantly decreased or increased acetate concentration relative to the control incubation. 
Table 1. Effect of dietary supplementation of herb extracts on volatile sulfur production in vitro by pig cecal bacteria. Means with standard deviations, $n=8$.

\begin{tabular}{lccc}
\hline Origin of plant extracts & $\mathrm{H}_{2} \mathrm{~S}^{*}$ & $\begin{array}{c}\mathrm{H}_{2} \mathrm{~S}(\mathrm{M})^{* *} \\
(\mathrm{ppm} / 24 \mathrm{~h} \text { in headspace gas })\end{array}$ & MeSH $^{* * *}$ \\
\hline None & $3,570 \pm 2,660^{\mathrm{a}}$ & $3,380 \pm 1,620^{\mathrm{ab}}$ & $14,750 \pm 1,630^{\mathrm{a}}$ \\
Ajuga decumbens & $1,450 \pm 1,240^{\mathrm{b}}$ & $4,680 \pm 1,240^{\mathrm{a}}$ & $11,420 \pm 2,420^{\mathrm{b}}$ \\
Mentha piperita & $1,310 \pm 1,050^{\mathrm{b}}$ & $1,310 \pm 1,050^{\mathrm{b}}$ & $11,400 \pm 2,640^{\mathrm{b}}$ \\
Perilla frutescens & $1,620 \pm 1,230^{\mathrm{b}}$ & $1,620 \pm 1,230^{\mathrm{b}}$ & $9,910 \pm 3,740^{\mathrm{b}}$ \\
ANOVA-p & 0.009 & 0.004 & 0.001 \\
\hline
\end{tabular}

$* \mathrm{H}_{2} \mathrm{~S}$ production in cultures without L-methionine.

${ }^{* *} \mathrm{H}_{2} \mathrm{~S}$ production in L-methionine-supplemented cultures.

*** MeSH (methanethiol) was measured in cultures supplemented with L-methionine.

${ }^{a, b}$ Values with different superscripts differ significantly by the post hoc Tukey-Kramer test, using the error variance of a preliminary ANOVA $(p<0.05)$.

Table 2. Effect of dietary supplementation of herb extracts on short-chain fatty acids and ammonia (mmol/kg digesta) in the pig cecal contents. Means with standard deviations, $n=8$.

\begin{tabular}{|c|c|c|c|c|c|}
\hline Origin of plant extracts & Acetate & Propionate & Butyrate & Total SCFA & $\mathrm{NH}_{3}$ \\
\hline None & $\begin{array}{c}84.5 \pm 3.7^{\mathrm{ab}} \\
\left(5.07 \pm 0.22^{\mathrm{ab}}\right)\end{array}$ & $\begin{array}{c}16.2 \pm 1.6 \\
(1.20 \pm 0.12)\end{array}$ & $\begin{array}{c}8.1 \pm 1.6 \\
(0.71 \pm 0.14)\end{array}$ & $\begin{array}{l}115.8 \pm 4.1 \\
(7.46 \pm 0.31)\end{array}$ & $10.5 \pm 2.1^{\mathrm{a}}$ \\
\hline Ajuga decumbens & $\begin{array}{c}86.7 \pm 3.6^{\mathrm{a}} \\
\left(5.20 \pm 0.21^{\mathrm{a}}\right)\end{array}$ & $\begin{array}{c}15.2 \pm 1.2 \\
(1.12 \pm 0.9)\end{array}$ & $\begin{array}{c}8.2 \pm 1.40 \\
(0.72 \pm 0.12)\end{array}$ & $\begin{array}{l}120.1 \pm 7.0 \\
(7.99 \pm 0.60)\end{array}$ & $8.4 \pm 2.0^{\mathrm{ab}}$ \\
\hline Mentha piperita & $\begin{array}{c}78.6 \pm 3.5^{b} \\
\left(4.72 \pm 0.21^{b}\right)\end{array}$ & $\begin{array}{c}19.4 \pm 5.7 \\
(1.44 \pm 0.42)\end{array}$ & $\begin{array}{c}7.9 \pm 1.46 \\
(0.70 \pm 0.13)\end{array}$ & $\begin{array}{l}114.8 \pm 7.6 \\
(7.20 \pm 0.59)\end{array}$ & $6.1 \pm 2.3^{b}$ \\
\hline Perilla frutescens & $\begin{array}{c}80.8 \pm 4.6^{\mathrm{ab}} \\
\left(4.85 \pm 0.28^{\mathrm{ab}}\right)\end{array}$ & $\begin{array}{c}20.5 \pm 7.0 \\
(1.52 \pm 0.52)\end{array}$ & $\begin{array}{c}8.1 \pm 2.00 \\
(0.71 \pm 0.18)\end{array}$ & $\begin{array}{c}117.2 \pm 12.4 \\
(7.42 \pm 1.00)\end{array}$ & $6.7 \pm 2.7^{\mathrm{ab}}$ \\
\hline ANOVA- $p^{*}$ & $\begin{array}{c}0.021 \\
(0.021)\end{array}$ & $\begin{array}{c}0.476 \\
(0.479)\end{array}$ & $\begin{array}{c}0.317 \\
(0.300)\end{array}$ & $\begin{array}{c}0.665 \\
(0.374)\end{array}$ & 0.038 \\
\hline
\end{tabular}

Values within parentheses are SCFA concentrations expressed as $\mathrm{g} / \mathrm{kg}$.

* A one way ANOVA was done to evaluate the effect of herb extracts.

${ }^{a, b}$ Values with different superscripts differ significantly by the post hoc Tukey-Kramer test, using the error variance of a one-way ANOVA $(p<0.05)$.

Table 3. Effect of dietary supplementation of herb extracts on the numbers of sulfate-reducing bacteria (SRB), bacteria producing sulfide from L-methionine, and bacteria producing methanethiol from L-methionine (log MPN/g digesta) in the pig cecal contents. Means with standard deviations, $n=4$.

\begin{tabular}{lccc}
\hline Origin of plant extracts & SRB & $\begin{array}{c}\mathrm{H}_{2} \text { S producers } \\
\text { from L-methionine }\end{array}$ & $\begin{array}{c}\text { Methanethiol producers } \\
\text { from L-methionine }\end{array}$ \\
\hline None & $8.6 \pm 0.36$ & $8.1 \pm 0.84$ & $7.8 \pm 0.87$ \\
Ajuga decumbens & $7.8 \pm 0.55$ & $7.0 \pm 0.85$ & $6.7 \pm 1.63$ \\
Mentha piperita & $8.1 \pm 0.55$ & $7.8 \pm 0.43$ & $7.5 \pm 0.75$ \\
Perilla frutescens L. & $8.6 \pm 0.53$ & $7.4 \pm 1.29$ & $7.4 \pm 1.30$ \\
ANOVA-p* & 0.442 & 0.323 & 0.683 \\
\hline
\end{tabular}

* A one-way ANOVA was done to evaluate the effect of herb extracts.

M. piperita extract significantly decreased ammonia concentration $(p<0.05)$.

Effect of dietary herb extracts on cecal bacterial numbers (Table 3)

MPNs of three functional groups of bacteria, SRB, producers of sulfide from sulfur amino acid (L-methionine), and producers of MeSH from L-methionine, did not vary by a supplementation of herb extracts.

\section{Active fraction of herb extracts (Fig. 1)}

n-Butanol fraction inhibited VS production most effectively among all three herb extracts. Unlike $M$. piperita and $A$. decumbens extracts, hexane and diethylether fractions of $P$. frutescens extract significantly reduced VS production in vitro. The residual fraction stimulated VS production. 

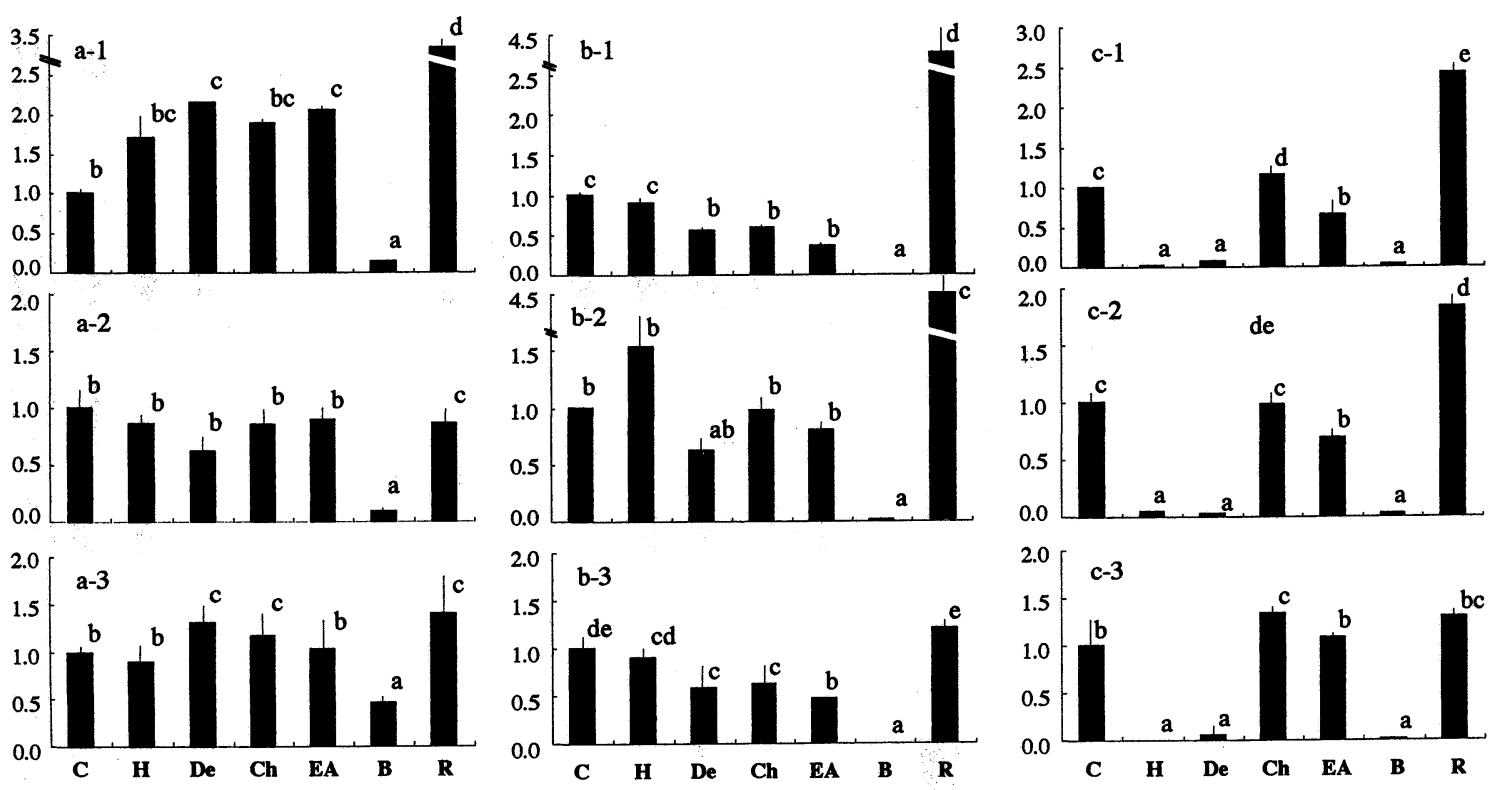

Fig. 1. Solvent fractionation of herb extracts and their effects on volatile sulfur compound production in batch cultures using pig cecal bacteria (Relative values to the control culture). a, b, c: Extracts of Ajuga decumbens, Mentha piperita, and Perilla frutescens, respectively. 1, 2, 3: Production of hydrogen sulfide and hydrogen sulfide in L-methionine-supplemented cultures, and methanethiol in L-methionine-supplemented cultures. For details, see text. C, control culture (vehicle control=dimethyl formamide); $\mathrm{H}$, hexane extracts; De, diethylether extracts; $\mathrm{Ch}$, chloroform extracts; EA, ethylacetate extracts; B, $n$-butanol extracts; R, residuals. $n=3$; bars with different superscripts differ significantly $(p<0.05)$ by the post hoc Tukey-Kramer test after ANOVA.

\section{DISCUSSION}

In a previous study, we screened several herb extracts that reduced $\mathrm{H}_{2} \mathrm{~S}$ production in a pure culture of SRB. In the present study, we tried to evaluate some of these extracts in vivo for their effect on VS production in the large intestine. Pig large intestine was used as a potential model for human large intestine because it is similar to that of human in certain aspects, such as fiber digestion, starch digestion, and bacterial flora composition (19-22).

To evaluate the effect of dietary herb extracts on VS production in the large intestine, in vitro incubation was carried out by the use of cecal digesta taken from pigs fed herb extracts. This technique was derived from a similar kind of experiment in which an antimethanogenic effect of dietary supplementation of a polyether antibiotic, monensin, or an elimination of rumen protozoa was evaluated $(23,24)$. The tendency observed by such in vitro culture technique $(23,24)$ was confirmed by in vivo experiments $(25,26)$. Therefore the technique is believed to be useful to estimate the production of gaseous compounds from digesta, which is difficult to measure in vivo.

We have previously confirmed in a preliminary experiment, using two cecally fistulated pigs, that the dose of ethanol used in the present study had no significant effect on the presently determined fermentation parameters. The pigs received the same diet as indicated above for $14 \mathrm{~d}$, and ethanol was thereafter supplemented for another $14 \mathrm{~d}$ in the preliminary study. The mean values of each two pigs (without ethanol vs. with ethanol) were 3,040 vs. 3,200 (ppm), 10,300 vs. 10,200 (ppm),
18,600 vs. 18,400 (ppm), 83.1 vs. 83.8 (mM), 11.9 vs. $10.3(\mathrm{mM}), 5.8$ vs. $6.1(\mathrm{mM})$, and 6.8 vs. $5.9(\mathrm{mM})$ for $\mathrm{H}_{2} \mathrm{~S}, \mathrm{H}_{2} \mathrm{~S}$ (from L-methionine), MeSH (from L-methionine), acetate, propionate, butyrate, and ammonia, respectively. Therefore we ignored the effect of ethanol in this experiment.

Three herb extracts significantly reduced cecal $\mathrm{H}_{2} \mathrm{~S}$ production in vitro (Table 1). The contribution of dissimilate sulfate reduction to cecal or colonic $\mathrm{H}_{2} \mathrm{~S}$ production is significant $(11,27)$. The reduction in $\mathrm{H}_{2} \mathrm{~S}$ production should be related to the decrease in dissimilatory sulfate reduction. The decrease in MPN of SRB by the herb extracts should reduce dissimilate sulfate reduction in cecal digesta. However, the reduction in MPN of SRB by herb extracts was statistically unclear (Table 3). Alternatively, the metabolism of SRB could be affected by herb extracts because the presently used extracts were primarily selected from more than 300 according to the inhibition of sulfide production by Desulfovibrio desulfuricans DSM 642 (11). However, the mode of action of herb extracts on the metabolism of SRB is not yet clear.

MeSH production was enhanced by the addition of L-methionine (Table 1). This enhancement helped the evaluation of the inhibitory effect of herb extract on MeSH production (Table 1). MeSH production from L-methionine was affected by herb extracts in this experiment. MeSH production requires L-methionine$\alpha$-deamino- $\gamma$-mercaptomethane-lyase (L-methioninase, EC 4.4.1.11) that catalyzes the $\alpha-\gamma$ elimination of methionine to produce methanethiol, ammonia, and $\alpha$-ketobutyrate. Several oral bacteria belonging to genera Fusobacterium, Eubacterium, Bacteroides, and 
Porphyromonas, as well as a soil bacterium, Clostridium sporogenes, have this enzyme and were identified as potent $\mathrm{MeSH}$ producers $(7,8)$. We have recently tested a range of laboratory strains and identified $C$. sporogenes JCM $1416^{\mathrm{T}}$ and $C$. bifermentans JCM $1386^{\mathrm{T}}$ as the most important $\mathrm{MeSH}$ producers. Further, we have isolated two strains of $C$. perfringens as potent MeSH producers from pig feces (9). Presently tested herb extracts possibly affected the metabolic activity of these bacteria because the numbers of MeSH producers did not vary by the supplementation of herb extracts (Table 3). MeSH production, desulfhydration of methionine, is coupled with deamination. The inhibition of MeSH production, therefore, should decrease ammonia production. The feeding of herb extracts indeed decreased ammonia production significantly (Table 2).

Cecal SCFA concentration was not affected by herb extracts (Table 2). This suggested that most of the bacteria-fermenting carbohydrates were not affected by herb extracts. The molar $(\mathrm{mmol} / \mathrm{kg})$ or weight $(\mathrm{mg} / \mathrm{kg})$ total of SCFA concentration was not affected by herb extracts. Therefore herb extracts had no visible negative effect on cecal and colonic carbohydrate digestion. This is important because SCFA production in the hindgut is important for the maintenance of gut function $(28,29)$.

The results from a successive solvent fractionation (Fig. 1) indicated that the $n$-butanol fraction of all three herb extracts contained the most effective compounds to reduce VS production. This fraction still contains compounds of different categories, such as lipopolysaccharides and saponosides (30). Saponosides have antimicrobial activities $(31,32)$. Saponosides of Yukka shidigera extract significantly reduce ruminal ammonia concentration (33). Saponosides therefore possibly depressed amino acid catabolism in the gut fermentation system. Two herb extracts, $M$. piperita and $A$. decumbens, were prepared as aqueous extracts; therefore they did not contain a great amount of nonpolar compounds such as aliphatic and aromatic hydrocarbons, usually known as bactericidal compounds, are found in essential oil of herb plants $(34,35)$. Unlike these extracts, $P$. frutescens was extracted by $50 \%$ aqueous ethanol. Accordingly, hexane and diethylether fractions of $P$. frutescens extracts should have contained reasonable amounts of effective compounds. Residual fraction should have contained water-soluble materials such as poly- or oligo-saccharides and amino acids that were used as substrates by cecal bacteria to stimulate VS production to some extents in vitro. The effect of whole herb extract on cecal VS production is therefore complex because some components could depress it and some others could stimulate it. In the solvent fractionation assay, we did not evaluate if these components could reach the large intestine. If the components of residual fraction were digested during passage through small intestine, then many of them were unlikely to affect cecal VS production in vivo. According to the present in vitro results, the components of herb extracts that depress VS production should reach the large intestine, and their effects were not masked by the stimulat- ing components of the same extracts.

In conclusion, the above results indicated that some herb plant or herb extracts contain substances that reduce VS production in the hindgut without significant side effects on carbohydrate fermentation.

\section{REFERENCES}

1) Roediger WEW, Moore J, Babidge W. 1997. Colonic sulfide in pathogenesis and treatment of ulcerative colitis. Dig Dis Sci 42: 1571-1579.

2) Florin THJ, Gibson GR, Neale JH, Cummings JH. 1990. A role for sulfate for reducing bacteria in ulcerative colitis? Gastroenterology 98: A170.

3) Gibson GR, Cummings JH, Macfarlane GT. 1991. Growth and activities of sulphate reducing bacteria in gut contents of healthy subjects and patients with ulcerative colitis. FEMS Microbiol Ecol 86: 103-112.

4) Roediger WE, Duncan A, Kapaniris O, Millard S. 1993. Reducing sulfur compounds of the colon impair colonocyte nutrition: implications for ulcerative colitis. Gastroenterology 104: 802-809.

5) Blom HJ, Chamuleau RA, Rothuizen J, Deutz NE, Tangerman A. 1990. Methanethiol metabolism and its role in the pathogenesis of hepatic encephalopathy in rats and dogs. Hepatology 11: 682-689.

6) Merino GE, Jetzer T, Doizaki WM, Najarian JS. 1975. Methionine-induced hepatic coma in dogs. Am J Surg 130: $41-46$.

7) Kreis W, Hession C. 1973. Isolation and purification of L-methionine- $\alpha$-deamino- $\gamma$-mercaptomethane-lyase (Lmethioninase) from Clostridium sporogenes. Cancer Res 33: $1862-1865$.

8) Persson S, Edlund MB, Claesson R, Carlsson J. 1990. The formation of hydrogen sulfide and methyl mercaptan by oral bacteria. Oral Microbiol Immunol 5: 195-201; Gastroenterology 110: A992.

9) Ushida K, Oshima N, Tanimura A, Miyazaki K, Kojima Y, Takakuwa S. 2001. Evaluation of methanethiol and hydrogen sulfide production by standard strains of intestinal bacteria and isolates from pig feces. Bioscience Microflora 20: 53-57.

10) Pitcher MCL, Beatty ER, Cummings JH. 1996. 5Aminosalicylic acid inhibits luminal sulfide production by gut bacteria in ulcerative colitis. Gastroenterology 110: A992.

11) Arakawa T, Ishikawa Y, Ushida K. 2000. Volatile sulfur production by pig cecal bacteria in batch culture and screening inhibitors of sulfate-reducing bacteria. J Nutr Sci Vitaminol 46: 159-164.

12) Church DC, Pond WG. 1974. Basic Animal Nutrition and Feeding, 296 p. O \& B Books, Corvallis, Oregon, USA.

13) The Ministry of Agriculture, Forestry and Fisheries. 1998. Japanese Feeding Standard for Swine (1998). 121 p. Central Association of Livestock Industry, Tokyo.

14) Ushida K, Sakata T. 1998. Effect of pH on oligosaccharide fermentation by porcine cecal digesta. Anim Sci Technol 69: 100-107.

15) Weatherburn MW. 1967. Phenol-hypochlorite reaction for determination of ammonia. Anal Chem 39: 971-974.

16) Ushida K, Fukusada S, Kojima Y. 1998. Effect of pH on dissimilatory sulfate reduction by porcine cecal microflora. Anim Sci Technol 69: 571-575.

17) Arakaki C, Mitsumori M, Itabashi H, Shirasaka S, 
Minato H. 1994. Influence of the presence of the presence of protozoa on the rumen microbial-population of cattle. J Gen Appl Microbiol 40: 215-226.

18) Yoshida M. 1975. Design of Experiments for Animal Husbandry. 473 p. Yokendo, Tokyo.

19) Graham H, Aman P. 1987. The pig as a model in dietary fibre digestion studies. Scand J Gastroenterol Suppl 129: 55-61.

20) McBurney MI, Sauer WC. 1993. Fiber and large bowel energy absorption: validation of the integrated ileostomy-fermentation model using pigs. J Nutr 123: 721-727.

21) Mitsuoka T, Kaneuchi C. 1977. Ecology of the bifidobacteria. Am J Clin Nutr 30: 1799-1810.

22) Topping DL, Gooden JM, Brown IL, Biebrick DA, McGrath L, Trimble RP, Choct M, Illman R. 1997. A high amylose (Amylomaize) starch raises proximal large bowel starch and increase colon length in pigs. $J$ Nutr 127: 615-622.

23) Ushida K, Miyazaki A, Kawashima R. 1982. Effect of Monensin on ruminal gas and VFA production of wethers fed high roughage ration. Jpn J Zootech Sci 53: $412-416$.

24) Ushida K, Miyazaki A, Kawashima R. 1986. Effect of defaunation on ruminal gas and VFA production in vitro. Jpn J Zootech Sci 57: 71-77.

25) Thornton JH, Owens FN. 1981. Monensin supplementation and in vivo methane production by steers. J Anim Sci 52: 628-634.

26) Vermorel M, Jouany JP. 1989. Effects of rumen protozoa on energy utilization by wethers of two diets based on ammonia-treated straw supplemented or not with maize. AJAS 2: 475-476.

27) Levine J, Ellis CJ, Furne JK, Springfield J, Levitt MD.
1998. Fecal hydrogen sulfide production in ulcerative colitis. Am J Gastroenterol 93: 83-87.

28) Macfarlane GT, Gibson GR. 1995. Microbiological aspects for the production of short-chain fatty acids in the large bowel. In: Physiological and Clinical Aspects of Short-Chain Fatty Acids (Cummings JH, Rombeau JL, Sakata T, eds), p 68-87. Cambridge University Press, Cambridge, UK.

29) Sakata T. 1995. Effects of short-chain fatty acids on the proliferation of gut epithelial cells in vivo. In: Physiological and Clinical Aspects of Short-Chain Fatty Acids (Cummings JH, Rombeau JL, Sakata T, eds), p 87-105. Cambridge University Press, Cambridge, UK.

30) Ng TB, Wong CM, Li WW, Yeung HW. 1986. A steryl glycoside fraction from Momordica charantia seeds with an inhibitory action on lipid metabolism in vitro. Biochem Cell Biol 64: 766-771.

31) Andersson L, Bohlin L, Iorizzi M, Riccio R, Minale L, Moreno-Lopez W. 1989. Biological activity of saponins and saponin-like compounds from starfish and brittlestars. Toxicon 27: 179-188.

32) Goultschin J, Palmon S, Shapira L, Brayer L, Gedalia I. 1991. Effect of glycyrrhizin-containing toothpaste on dental plaque reduction and gingival health in humans. A pilot study. J Clin Periodontol 18: 210-212.

33) Wallace RJ, Arthaud L, Newbold CJ. 1994. Influence of Yucca shidigera extract on ruminal ammonia concentrations and ruminal microorganisms. Appl Environ Microbiol 60: 1762-1767.

34) Deans SG, Ritchie G. 1987. Antibacterial properties of plant essential oils. Int J Food Microbiol 5: 165-180.

35) Morris JA, Khettry A, Seitz EW. 1979. Antimicrobial activity of aroma chemicals and essential oils. J Am Oil Chem Soc 56: 595-603. 